\title{
Doğum Ağrısının Yönetiminde Farmakolojik Olmayan Ebelik Uygulamaları
}

\author{
Nonpharmacological Midwifery Practices in the Management of Labor Pain
}

\author{
Nükhet KAÇAR* iD
}

\begin{abstract}
ÖZET
Doğum, her kadın için özel bir süreçtir. Doğumun fizyolojisinden kaynaklanan ă̆rı, gebenin doğum sürecini doğrudan etkilemektedir. Doğum ă̆rısı yönetilebilen bir ă̆rıdır ve bu ă̆rının yönetimi; iyi bir ebelik bakımı ile să̆lanabilir. Bu yüzden ebeler, ağr yönetiminde farmakolojik olmayan yöntemleri intrapartum bakıma dahil ederek, doğum ağrısının yönetiminde aktif rol almalıdır. Ebeler, gebenin karar verme sürecine katılmasını sağlayarak; ăgrıyla baş etmek için kullanılacak farmakolojik olmayan yöntemleri, kendi otonomisiyle uygulamalıdır. Bu amaçla; ebeler ağrının yönetiminde farmakolojik olmayan yaklaşımları takip etmeli; kanıta dayalı yöntemleri, gebeye özgü bireyselleştirilmiş ebelik bakımıyla uygulamalıdır. Bu derlemenin amacı; doğum ăgrısının yönetiminde kullanılabilecek farmakolojik olmayan yöntemlerin detaylı incelenmesi ve bu yöntemler ile ilgili yapılan çalışmaların sonuçlarının belirlenmesi ile ebelik mesleği başta olmak üzere tüm să̆lık profesyonellerine katkı sağlamaktır.
\end{abstract}

Anahtar Kelimeler: Ebelik, doğum ă̆rısl, farmakolojik olmayan yöntemler, doğum

\begin{abstract}
Childbirth is a special process for every woman. Pain which is caused by labor's physiology, directly affects the labor process of the pregnant. Labor pain can be managed and the management of this pain could be provided with well midwifery care. So, midwives should take an active part in management of this pain by incorporating nonpharmacological methods into intrapartum care. Midwives should apply the pharmacologic methods with own autonomy by supporting participation of the pregnant in the decision making process. With this aim, midwives should follow nonpharmacologic approaches in pain management and should apply evidence based methods with individualized midwifery care special to pregnant. The purpose of this review is to examine nonpharmacological methods detailed that can be used in management of labor pain and midwifery profession being in the first place to contribute to healthcare professionals by determining results of works made about these methods.
\end{abstract}

Keywords: Midwifery, labor pain, non pharmacological methods, labor

* Uzman Ebe, Ankara Şehir Hastanesi-Kadın Doğum Hastanesi, Doğum Salonu

Sorumlu Yazar / Corresponding Author: Nükhet Kaçar,nk.nukhetkacar@gmail.com 


\section{GİRIŞ̧}

Doğum süreci; gelişimini tamamlamış olan fetüsün, uterus kontraksiyonları ve eşlik eden birtakım yardımcı mekanizmaların katkısı ile doğum kanalından geçmesi ve sonrasında, fetüs ve diğer konsepsiyon ürünlerinin dışarıya atılmasından oluşmaktadır (Kömürcü, 2013; İpek, 2014; Türkmen, 2017). DSÖ doğum sürecinin başlama zamanını, 22. gebelik haftasından sonra vajinadan su gelmesi, kan lekeli mukus akıntısının olması, aralıklı karın ağrısı ya da kasılma varlı̆ğ ile serviksin incelmesi veya servikal çapta artışın olması olarak tanımlamaktadır (World Health Organization [WHO], 2017).

\section{Doğum A $\breve{g r ı s ı ~}$}

Doğum ağrısı birçok faktöre göre değişiklik gösteren subjektif bir yapıya sahiptir. Normal bir sürecin parçası olan doğum ağrısı diğer ağrılardan farklı olarak; doğumun ilerlemesini, anne ve bebeğin buluşmasını sağlayan hormonların uyumlu çalıştı̆̆ı fizyolojik özelliklere sahiptir. Bu ağrı için gebenin hazırlanma zamanı vardır. Dolayısıyla gebelerin ağrıyla baş etme ve ağrıyı yönetme yetisini geliştirmek için doğuma hazırlık eğitimi verilmelidir (Kömürcü, 2013; Gaskin, 2015; Gonzalez, Trehan \& Kamel, 2016; Bonapace et al., 2018).

Doğum ağrısı, doğumun evrelerine göre farklılık göstermektedir. Doğumun birinci evresindeki ağrı çoğunlukla uterus kasılmaları ve serviksin uyarılmasından kaynaklanan doku özellikli ağrıken, ikinci evredeki ağrı vajina ve perinede gerilme, uterus ve pelvik organlar üzerinde traksiyon, pelvik taban kaslarının distansiyonu nedeniyle somatik özelliktedir. Doğumun üçüncü ve dördüncü evresindeki ağrı ise doku hasarı ve travmaya bağlı özellik göstermekte ve plasentanın atılması ve uterus involüsyonundan kaynaklanmaktadır (Gonzalez et al., 2016).

\section{Doğum Ăgrısının Yönetilmesi}

Obstetrik bakımın vazgeçilmez bir parçası olan doğum ağrısının yönetilmesi; prepartum, intrapartum ve postpartum bakım maliyetinin azaltılmasını sağlamaktadır. Doğum ağrısının yönetimi için farmakolojik olmayan yöntemler hakkında gebeye bilgi vererek gebe karar verme sürecine dahil edilmelidir. Kadının dahil edilmediği bir süreç kadını bağımlı kılmakta ve sağlık personelini zorlamaktadır (Simkin \& Bolding, 2004).

Doğum sürecinde yaşanan ağrı, gebe ve ebenin birlikte yönetmesi gereken bir ağrıdır. Doğum ağrısının yönetiminde gecikme veya yönetimin niteliğinin yetersiz oluşu; olumsuz doğum deneyimi, negatif ebelik ve doğum algısına sebep olabilir. Bu yüzden ebeler, doğum eylemi süresince her gebeye; pozitif iletişim dilini temel alarak bireyselleştirilmiş bakım planı sağlamalı ve doğum sürecinde gebenin doğum ağrısıyla baş edebilmesine destek olmalıdır. Doğum ağrısının yönetiminde kullanılacak farmakolojik olmayan yöntemi gebe ile birlikte kararlaştıran ebe, bu yöntemi kendi otonomisi ile uygulayıp, annenin daha konforlu bir doğum süreci geçirmesini sağlayabilir. Aynı 
zamanda gebede daha iyi bir ebelik ve doğum algısı oluşturabilir, gebenin ebesiyle doğum yapma isteğini de artırabilir.

$\mathrm{Bu}$ derlemenin amacı; intrapartum bakımın vazgeçilmez ögesi ve ebelik bakımının bağımsız rolü olan, doğum ağrısının yönetiminde farmakolojik olmayan ebelik uygulamalarının çeşitlerini, uygulanış biçimlerini ve doğum sürecine etkilerini alanyazın taraması yaparak incelemek ve ebelik mesleği başta olmak üzere tüm sağlık profesyonellerine katkı sağlamaktır.

\section{YÖNTEM}

$\mathrm{Bu}$ derlemede, doğum ağrısını gidermeye yönelik kullanılan farmakolojik olmayan yöntemleri belirlemek için Google ve Google Akademi Türkçe arama motorları üzerinde, 15.05.2019-20.05.2019 tarih aralığında İngilizce "labor pain", "management of labor pain", non-pharmacological methods in management of labor pain" ve "midwife and labor pain" anahtar kelimeleri ile Türkçe "doğum ağrısı", “doğum ağrısının yönetimi”, "doğum ağrısının yönetiminde farmakolojik olmayan yöntemler” ve "ebe ve doğum ağrısı" anahtar kelimeleri ile Google Akademik, Science Direct, Wiley Online Library, Pubmed, Cochrane Library ve Ulusal Tez Merkezi veri tabanlarında taranarak yapılmıştır.

Derlemeye 2000-2019 tarihleri arasında yayınlanan ve tam metnine ulaşılabilen Türkçe ve İngilizce yayınlanmış, tanımlayıcı, randomize kontrollü çalışmalar, sistematik inceleme makaleleri ve tez çalışmaları dahil edilmiştir. Konu hakkında bilgi veren derlemeler, raporlar ve rehberler çalışma dışı bırakılmıştır. Konu ile ilgisi olmayan ve birbirinin tekrarı olan araştırma makaleleri de çıkarıldıktan sonra geriye 138 makale değerlendirmeye alınmıştır.

Doğum ağrısının yönetiminde kullanılan farmakolojik olmayan yöntemler taramanın yapıldığı tarih başlangıcı olan 2000'li yıllardan itibaren kullanılmakta ve bu kullanım oranı yıllar içerisinde artma trendi göstermektedir. Bu yöntemlerin kullanımı ile ilgili çalışmalar da yıllar ile paralellik göstererek artmaktadır.

$\mathrm{Bu}$ derlemede doğum ağrısını azaltmada kullanılan farmakolojik olmayan yöntemlerden her bir yönteme ait en güncel ve geniş sonuçlara sahip çalışmalara, meta analizlere ve sistematik derlemelere yer verilerek toplam 40 çalışma ile yöntemler açıklanmıştır. Derlemede yer verilen kaynakların veri tabanlarına göre dağılımı Tablo 1'de ve yöntemlere göre dağılımı ise Tablo 2'de gösterilmektedir. (Tablo 1, Tablo 2). 
Tablo 1. Kaynakların veri tabanlarına göre sınıflandırılması

\begin{tabular}{|c|c|}
\hline Veri Tabanı & Yazarlar \\
\hline Pubmed & $\begin{array}{l}\text { (Simkin \& Bolding, 2004; Fogarty, 2008; Hutton et al., 2009; Derry et al., } \\
\text { 2012; Hajiamini et al., 2012; Mollamahmutoğlu ve ark., 2012; Mortazavi et al., } \\
\text { 2012; Allameh et al., 2015; Dong et al., 2015; Bolbol-Haghighi et al., 2016; } \\
\text { Lakhan et al., 2016; Bonapace et al., 2018; Ranjbaran et al., 2017; Ghiasi et al., } \\
\text { 2019; Suarez et al., 2019) }\end{array}$ \\
\hline Science Direct & (Taavoni et al., 2016; Shahoei et al., 2017; Ünalmış 2017; Ali \& Hamdia 2018) \\
\hline Cochrane Library & (Lawrence et al., 2013; Madden et al., 2016) \\
\hline Researchgate & $\begin{array}{l}\text { (Askari et al., 2016; Regis et al., 2017; Tektaş ve ark., 2017; Veyilmuthu et al., } \\
\text { 2017) }\end{array}$ \\
\hline $\begin{array}{l}\text { Diğer Veri Tabanları } \\
\text { (Google Scholar, Ulusal Tez } \\
\text { Merkezi, Korean Journal, } \\
\text { Iranian Journal Vb. } \\
\text { Alanında İndeksli Ulusal } \\
\text { Dergiler) }\end{array}$ & $\begin{array}{l}\text { (Karami et al., 2007; Hashemi et al., 2012; Barbieri et al., 2013; Ghani, 2014; } \\
\text { İpek, 2014; Vaziri et al., 2014; Ganji et al., 2015; Rastegarzade et al., 2015; } \\
\text { Ahmad-Shirvani \& Ganji, 2016; Altıparmak ve Coşkun, 2016; Mamuk, 2017; } \\
\text { Gönenç ve Çakırer Çalbayram, 2017; Hu et al., 2017; Mardliyana et al., 2017; } \\
\text { Payendah et al., 2017; Türkmen, 2017; Yılmaz Esencan ve ark., 2018; Rajiani } \\
\text { et al., 2019) }\end{array}$ \\
\hline
\end{tabular}


Tablo 2. Kaynakların yöntemlere göre sınıflandırılması

\begin{tabular}{|c|c|c|}
\hline Yöntem & Yazar & Çalışma Türü \\
\hline Doğuma Hazırlık Kursu & $\begin{array}{l}\text { (Altıparmak ve Coşkun, 2016; Gönenç ve } \\
\text { Çakırer Çalbayram, 2017; Yılmaz Esencan } \\
\text { ve ark., 2018) }\end{array}$ & Araştırma Makalesi \\
\hline Yoga & (Smith et al., 2018) & Cochrane Sistematik Derlemesi \\
\hline $\begin{array}{l}\text { Hareket Özgürlüğ̈̈, } \\
\text { Yürüyüss, Pozisyon } \\
\text { Değişikliği }\end{array}$ & $\begin{array}{l}\text { (Simkin \& Bolding, 2004; Lawrence et al., } \\
\text { 2013) }\end{array}$ & $\begin{array}{l}\text { Araştırma Makalesi, Cochrane } \\
\text { Sistematik Derlemesi }\end{array}$ \\
\hline $\begin{array}{l}\text { İntradermal Su Blokları, } \\
\text { Steril Su Enjeksiyonu }\end{array}$ & $\begin{array}{l}\text { (Fogarty, 2008; Hutton et al., 2009; Derry et } \\
\text { al., 2012; Mamuk, 2017) }\end{array}$ & $\begin{array}{l}\text { Araştırma Makalesi, Cochrane } \\
\text { Sistematik Derlemesi }\end{array}$ \\
\hline Solunum Teknikleri & $\begin{array}{l}\text { (Simkin \& Bolding, 2004; Bonapace et al., } \\
\text { 2018) }\end{array}$ & $\begin{array}{l}\text { Araştırma Makalesi, SOGC Klinik } \\
\text { Uygulama Kılavuzu }\end{array}$ \\
\hline Gevşeme, Refleksoloji & (Bonapace et al., 2018; Smith et al., 2018) & $\begin{array}{l}\text { SOGC Klinik Uygulama Kılavuzu, } \\
\text { Cochrane Sistematik Derlemesi }\end{array}$ \\
\hline Müzik & $\begin{array}{l}\text { (Simkin \& Bolding, 2004; Bonapace et al., } \\
\text { 2018; Smith et al., 2018) }\end{array}$ & $\begin{array}{l}\text { Araştırma Makalesi, SOGC Klinik } \\
\text { Uygulama Kilavuzu, Cochrane } \\
\text { Sistematik Derlemesi }\end{array}$ \\
\hline $\begin{array}{l}\text { Doğum Havuzu, Banyo, } \\
\text { Duș, Hidroterapi }\end{array}$ & $\begin{array}{l}\text { (Mollamahmutoğlu ve ark., 2012; Barbieri } \\
\text { et al., 2013) }\end{array}$ & Araştırma Makalesi \\
\hline Akupunktur, Akupressür & $\begin{array}{l}\text { (Allameh et al., 2015; Dong et al., 2015; } \\
\text { Rastegarzade et al., 2015) }\end{array}$ & Araştırma Makalesi \\
\hline $\begin{array}{l}\text { Hipnoz, Hipnoterapi, } \\
\text { Hipnoz İle Doğum } \\
\text { (Hipnobirting) }\end{array}$ & $\begin{array}{l}\text { (Simkin \& Bolding, 2004; Madden et al., } \\
\text { 2016) }\end{array}$ & $\begin{array}{l}\text { Araştırma Makalesi, } \\
\text { Sistematik Derlemesi }\end{array}$ \\
\hline $\begin{array}{l}\text { Transkütan Elektriksel } \\
\text { Sinir Uyarımı }\end{array}$ & $\begin{array}{l}\text { (Payendah et al., 2017; Regis et al., 2017; } \\
\text { Shahoei et al., 2017; Veyilmuthu et al., } \\
\text { 2017; Suarez et al., 2019) }\end{array}$ & Araştırma Makalesi \\
\hline $\begin{array}{l}\text { Aromaterapi } \\
\text { Sicak Ve Soğuk Uygulama, } \\
\text { Paket, Terapi }\end{array}$ & $\begin{array}{l}\text { (Lakhan et al., 2016; Ghiasi et al., 2019) } \\
\text { (Ghani, 2014; Vaziri et al., 2014; Ahmad- } \\
\text { Shirvani \& Ganji, 2016; Taavoni et al., } \\
\text { 2016; Mardliyana et al., 2017) }\end{array}$ & $\begin{array}{l}\text { Sistematik Derleme ve Meta Analiz } \\
\text { Randomize Kontrollü Çalışma, } \\
\text { Araştırma Makalesi }\end{array}$ \\
\hline $\begin{array}{l}\text { Masaj Terapisi, Tedavisi, } \\
\text { Uygulaması }\end{array}$ & $\begin{array}{l}\text { (Simkin \& Bolding, 2004; Karami et al., } \\
\text { 2007; Hajiamini et al., 2012; Hashemi et al., } \\
\text { 2012; Mortazavi et al., 2012; Ganji et al., } \\
\text { 2015; Askari et al., 2016; Bolbol-Haghighi } \\
\text { et al., 2016; Hu et al., 2017; Tektas ve ark., } \\
\text { 2017; Ranjbaran et al., 2017; Ali \& Hamdia, } \\
\text { 2018; Smith et al., 2018, Rajiani et al., } \\
\text { 2019) }\end{array}$ & $\begin{array}{l}\text { Araştırma Makalesi, } \quad \text { Sistematik } \\
\text { Derleme, Randomize Kontrollü } \\
\text { Çalışma, Sistematik Derleme ve } \\
\text { Meta Analiz, Cochrane Sistematik } \\
\text { Derlemesi }\end{array}$ \\
\hline
\end{tabular}

\section{Doğum Ağrısının Yönetilmesinde Farmakolojik Olmayan Yöntemler}

Doğum sürecindeki müdahalelerin artmasıyla birlikte birçok profesyonel dernek; ağrı yönetimi için farmakolojik olmayan yöntemleri desteklemekte ve klinik rehberlerin geliştirilmesini önermektedir (Bonapace et al., 2018). Ağrıya farmakolojik olmayan yaklaşımda sağlık profesyonelleri, ağrıyı ortadan kaldırmayı değil, ağrıyla başa çıkabilmeyi sağlamalı ve iyi bir rehberlik sunmalıdır (Simkin \& Bolding, 2004). 


\section{Doğuma Hazırlık Kursu}

Gebelerin doğuma hazırlanması için oluşturulmuş kurslardır. İlk kurs programı Grantly Dick Read tarafından gebenin doğum sırasında karın solunum egzersizleri yapması ve gevşemesiyle birlikte doğum korkusu ve ağrısıyla başa çıkabileceğini ileri sürmesi ile geliştirilmiştir. Bradley yöntemi ise eşin koçluğunu vurgulayarak doğumun eşler arasında paylaşılması gereken bir deneyim olduğunu temel almaktadır. Lamaze yöntemi kadının bilinçli bir şekilde nefes almasını sağlayarak, solunum kontrol mekanizması ile kasların gevşemesini ve doğum ağrısının azalmasını hedefleyen psikoprofilaktik bir yöntemdir. Mongan yöntemi pozitif doğum dilini kullanan hypnobirthing temelli bir metottur. Farkındalığa dayalı doğum ve ebeveynlik modeli ise eğitimlerinde yoga, meditasyon gibi konulara değinmektedir. England yönteminde rol-play yapma, maket yapma, resim çizme gibi teknikler kullanılarak, gebenin yaşadıklarının anlaşılmasına odaklanılmaktadır. Doğuma hazırlık kursu, sınıf düzeni, kişi sayısı ve konular önceden belirlenmelidir (Simkin \& Bolding, 2004).

Doğuma hazırlık eğitimi alan gebelerin doğum ağrısı ile baş ettiği, yarı oturur pozisyonda doğum yaptığı (Gönenç ve Çakırer Çalbayram, 2017), doğum öncesi eğitimden memnun kaldığ1 (Altıparmak ve Coşkun, 2016), tentene teması isteme ve uygulama, ilk emzirme zamanı ve doğum şekli ile ilgili anlamlı bir ilişkisi olduğu (Yılmaz Esencan ve ark., 2018) bulunmuştur.

\section{Yoga}

Yoga esneklik ve güç egzersizlerini; nefes, gevşeme ve meditasyonla birleştiren bir tekniktir. Kadınları doğum için hazırlayarak endorfin salınımını sağlar. Doğum öncesi eğitimlerde nefes egzersizi, meditasyon ve yoga konuları da anlatılmaktadır (Bonapace et al., 2018). Cochrane sistematik derlemesinde yoga yapan gebelerin, doğum ağrısı şiddet seviyelerinin daha az olduğu ve yogadan memnun oldukları sonucuna ulaşılmıştır (Smith, Levett, Collins \& Jones, 2018).

\section{Hareket Özgürlü̆̆̈̈̈/Yürüyü̈ş/Pozisyon Değişikliği}

Kadınlar doğum ağrısıyla baş ederken yürüyüş yapmak, hareket etmek ve pozisyon değiştirmek yönünde eğilim göstermektedir (Simkin \& Bolding, 2004). Lawrence ve arkadaşları (2013), yapmış oldukları bir Cochrane sistematik derlemesinde 5218 kadını incelemeye almıştır. Çalışmanın sonucunda doğum sürecinde dik ve harekete izin veren pozisyonları uygulayan kadınlarda, uygulamayan kadınlara göre; doğumun birinci evresinin süresinin yaklaşık bir saat 22 dakika kısaldığı, epidural analjezi ihtiyacı ile kullanım oranının daha az olduğu ve sezaryen doğum oranının düştüğü bildirilmiştir (Lawrence, Lewis, Hofmeyr \& Styles, 2013).

\section{Intradermal Su Blokları/Sterile Su Enjeksiyonu}

İntradermal su bloklarının kullanımı, doğumdaki bel ağrısını azaltmakta etkilidir. İntradermal su blokları, posterior superior iliak omurganın üzerine dört tane 0,05 ila $0,1 \mathrm{ml}$ steril su enjeksiyonu 
uygulanması ile yapılır (Simkin \& Bolding, 2004; Martensson et al., 2018). Derry ve arkadaşlarının (2012), 766 kadını inceledikleri Cochrane sistematik derlemesinde; uygulama yapılan kadınların daha az bel ağrısı algıladıkları belirtilmiştir (Derry, Straube, Moore, Hancock \& Collins, 2012). Yapılan başka bir sistematik derlemede, doğum eyleminde steril su enjeksiyonu uygulanan kadınların sezaryen doğum oranının daha düşük olduğu bulunmuştur (Hutton, Kasperink, Rutten, Reitsma \& Wainman, 2009). Doğum sırasında steril su enjeksiyonu uygulanan kadınlarda, uygulanmayan kadınlara oranla; bel ağrısının daha az olduğu başka bir çalışmanın sonucunda bildirilmiştir (Mamuk, 2017). Fogarty'nin 2008 yılında 6 randomize kontrollü çalışmayı dahil ettiği sistematik derlemesinde ise, doğum eylemi sırasında steril su enjeksiyonu uygulanan kadınların; doğumda bel ağrılarının 10 dakika ila 2 saat arasında azaldığı sonucuna varmıştır (Fogarty, 2008).

\section{Solunum Teknikleri}

Doğum ağrısını yönetmede kullanılan farmakolojik olmayan yöntemlerden biri olan solunum teknikleri hem sakinleşmeyi sağlar hem de kadının kontrol duygusunu artırır. Çalışmalarda solunum tekniği kullanan gebelerin, memnuniyet düzeylerinin yüksek, vajinal yırtıkların düşük ve ağrı algısının daha az olduğu bulunmuştur. Solunum egzersizleri kullanan kadınların; bebeklerinin özel bir bakım odasında kalmasını isteme oranının düşük olduğu belirtilmiştir. Aynı zamanda bu kadınların ebeveyn olma sürecine daha hakim olduğu ve bebekleri ile bağlanmasının daha güçlü olduğu bulunmuştur (Simkin \& Bolding, 2004; Bonapace et al., 2018).

\section{Gevşeme/Refleksoloji}

Refleksoloji sinir noktalarının uyarılması sonucu elektrokimyasal mesajların oluşumuna ve endorfin salınımına yol açan invaziv olmayan bir ağrı rahatlatma yöntemidir (Bonapace et al., 2018). Cochrane sistematik derlemesinde gevşeme teknikleri kullanan kadınların doğum ağrısının azaldığı ve uygulamadan memnun kaldıkları sonucuna ulaşılmıştır (Smith et al., 2018). Obstetrik alanda uygulanan refleksolojinin uterus kontraksiyonlarının düzenlenmesi, deneyimlenen ağrı ve kaygı düzeyinin azaltılması, oksitosin salınımının uyarılması, doğumun ilerlemesi ve eylemin süresinin k1saltılmasında etkili olduğu belirtilmektedir (Bonapace et al., 2018).

\section{Müzik}

Beynin sağ yarım küresinden algılanan müzik, hipofiz bezini endorfin salgılanması için uyarabilir (Simkin \& Bolding, 2004). Cochrane sistematik derlemesinde doğumun latent fazında müzik dinletilen gebelerin doğum ağrı skorları daha düşük bulunmuştur (Smith et al., 2018). Obstetrik alanda kaygıyı azaltmak, dikkati dağıtmak, kontrol duygusu ve gevşemeyi artırmak, doğum ağrısını azaltmak için kullanılabilir. Kadının müziğini kendi seçmesi kendisine kontrol hissi verir (Simkin \& Bolding, 2004; Bonapace et al., 2018). 


\section{Doğum Havuzu/Banyo/Duşs/Hidroterapi}

Doğumda suyun kullanımı üzerine yapılan ilk bilimsel yayın 1973 yılında yayınlanmıştır (Simkin \& Bolding, 2004). Doğum sürecinde uygulanan hidroterapi ile ilgili yapılan çalışmalarda, hidroterapi kullanan kadınların anksiyete ve ağrı skorları daha düşük, doğumun 2. ve 3. evresi daha kısa, indüksiyon ve epizyotomi ihtiyacının daha az (Mollamahmutoğlu ve ark., 2012; Barbieri, Henrique, Chors, Maia \& Gabrielloni, 2013) olduğu bulunmuştur.

\section{Akupunktur/Akupresür}

Akupunktur fizyolojik fonksiyonları kontrol ederek organizmadaki doku hasarların düzeltmektedir. Vücutta 12 adet meridyen ve 365 adet akupunktur noktası vardır. Belirli noktaların birleşiminde cilde ince iğnelerin batırılması ardından iğnelerin döndürülmesi, 1sıtılması veya elektriksel uyarılmasıyla, vücuttaki rahatsız edici semptomlar hafifletilir (Simkin \& Bolding, 2004). Ağrının iletim teorilerinden kapı kontrol teorisine göre, nörolojik sistemdeki kapı mekanizmaları belirli sayıda ağrı uyaranlarını iletmektedir. Dolayısıyla ağrı yerine başka uyaranların bilince gönderilmesiyle ağrı azalmaktadır. Akupunktur/akupressür uygulaması, kapı kontrol teorisindeki kapı mekanizmalarından geçerek, ağrı uyaranın kapıdan geçmesini ve bilince ulaşmasını engellemektedir. Bilince ulaşan akupunktur/akupressür uygulaması ağrı geçişini engellediği için doğum ağrısını azaltmaktadır (Bonapace et al., 2018). Akupunktur/akupresür uygulanan gebelerle yapılan çalışmalarda; gebelerin doğum süresi ve ağrı skoru (Allameh, Tehrani \& Ghasemi, 2015; Dong, Hu, Liang \& Songying, 2015; Rastegarzade, Abedi, Valiani \& Haghighi, 2015) daha düşük bulunmuştur.

\section{Hipnoz/ Hipnoterapi/ Hipnoz ile Doğum (Hipnobirthing)}

Hipnoz 19. yüzyılın başlarından beri doğum ağrılarını azaltmak için kullanılmaktadır (Simkin \& Bolding, 2004). Madden ve arkadaşlarının (2016), 2954 kadını inceledikleri Cochrane sistematik derlemesinde hipnozun ağn düzeyi ve analjezi ihtiyacını azalttığı bulunmuştur (Madden, Middleton, Cyna, Matthewson \& Jones, 2016). Mevcut kanttlar hipnozun doğumdaki ağrıyı azaltmada etkili olabileceğini göstermektedir (Simkin \& Bolding, 2004).

\section{Transkütan Elektriksel Sinir Uyarımı (TENS)}

Derialtı elektriksel sinir stimülasyonu, düşük voltajlı elektrik darbelerinin el tipi bir pille çalışan jeneratörün yüzey elektrotları ile cilde aktarılmasıdır. Doğum ağrısını azaltmak için bir çift elektrot T10-L1 seviyesine, diğeri S2 ila S4 seviyesine paralel yerleştirilir. Kadın bir kadranı çevirerek akımın yoğunluğunu kontrol eder ve TENS ünitesindeki kadranları ayarlayarak yoğunluğu değiştirebilir. Transkütan elektriksel sinir uyarımı, karıncalanma hissine sebep olur (Simkin \& Bolding, 2004). Transkütan elektriksel sinir uyarımı uygulaması ile ilgili yapılan çalışmalarda, TENS'in doğum ağrısını belirgin bir şekilde azalttığı ve farmakolojik ajan kullanımını ertelediği bildirilmiştir 
(Payendah, Nassiri, Nahidi \& Fouladi, 2017; Regis et al. 2017; Shahoei, Shahghebi, Rezai \& Naqshbandi, 2017; Veyilmuthu, Govindan, Venugopalan \& Panicker, 2017; Suarez et al., 2019).

\section{Aromaterapi}

Bitkilerden damıtılmış konsantre esansiyel yağlar veya esansları kullanma bilimidir. Obstetrik alanda korku, endişe ve ağrıyı azaltmak, refah duygusunu artırmak, amacıyla kullanılabilir (Simkin \& Bolding, 2004). Aromaterapi kullanımı ile ilgili yapılan sistematik derlemelerde; aromaterapinin doğum ağrısını (Lakhan, Sheafer \& Tepper, 2016) ve anksiyete düzeyini (Ghiasi, Bagheri \& Haseli, 2019) etkin bir şekilde azaltabileceği bildirilmiştir.

\section{Sicak ve Soğuk Uygulama/Paket/Terapi}

Farklı sıcaklıklarda çeşitli materyallerle türlü bölgelere yapılan yüzeysel uygulamalardır. Isı kaynakları arasında; sıcak su şişesi, ısıtılmış pirinç, dolgulu çorap, sıcak kompres, elektrikli ısıtma yastığı, sıcak battaniye, sıcak banyo veya duş vardır. Soğuk uygulama formları; buzla dolu eldiven veya torba, donmuş jel paketi, buz dolu şişe, soğuk suya daldırılmış bez ve dondurulmuş sebzeler olabilir. Sıcak ve soğuk uygulama ile ilgili yapılan çalışmalar; bu uygulamaların, ağrının azaltılması ile enflamasyon, ödem ve kas spazmının giderilmesi için kullanılabilirliğini göstermektedir (Simkin \& Bolding, 2004).

Sıcak terapi uygulanan kadınlar ile yapılan çalışmalarda, bu kadınların doğum ağrısı algıları (Ahmad-Shirvani \& Ganji, 2016; Taavoni, Sheikhan, Abdolahian \& Ghavi, 2016) ve perineal travma ile ağr1 düzeyleri (Vaziri et al., 2014) daha düşük bulunmuştur. Başka bir çalışmada; soğuk uygulamanın doğum ağrısını ve doğum süresini azalttığı, maternal-fetal sağlı üzerinde olumsuz bir etki yaratmadığı sonucuna ulaşılmıştır (Ahmad-Shirvani \& Ganji, 2016; Mardliyana, Raden \& Hani, 2017). Sıcak ve soğuk uygulamanın birlikte değerlendirildiği çalışmalarda ise; uygulama yapılan kadınların doğum ağrısı ve kaygı düzeyleri daha düşük, doğumdan memnuniyet düzeyleri daha yüksek (Ghani, 2014) bulunmuştur.

\section{Masaj Terapisi/ Tedavisi/Uygulamast}

Gebe kadına dokunmak, pozitif iletişim, güven ve kaliteli bakımı sağlar. Yapılan çalışmalarda masaj tekniği kullanılan kadınların doğumlarında, masaj tekniği kullanılmayan kadınlara göre, vajinal yırtık ve forseps kullanımı oranı daha az, ruh halleri daha iyi, daha az ağrı, anksiyete içinde ve daha fazla güvende hissettikleri bulunmuştur (Simkin \& Bolding, 2004).

Masaj uygulamasının doğum sürecinde kullanımı ile ilgili yapılan çalışmalarda; masajın doğum ağrısını (Mortazavi, Khaki, Moradi, Heidari \& Rahimparvar, 2012; Askari, Alavi \& Dashtinezhad, 2016; Hu, Brettle, Jiang \& Zeng, 2017; Rajiani, Hendra, Sudirman, Sumami \& Hartati, 2019), süresini (Askari et al., 2016; Bolbol-Haghighi, Masoumi \& Kazemi, 2016) ve doğumla ilgili stresi (Mortavazi 
et al., 2012) azalttığı bulunmuştur. Aynı zamanda doğum memnuniyetinin arttığı sonucuna ulaşılmıştır (Mortavazi et al., 2012). Başka bir çalışmada da, masaj yapılan kadınların yenidoğanlarının 1. ve 5 . dakikadaki apgar değerlendirmesinin daha yüksek olduğu ve masajın gebelerde psikolojik iyilik halini artırdığı bildirilmiştir (Bolbol-Haghighi et al., 2016).

Masaj ile diğer teknikleri kıyaslayan çalışmalara bakıldığında; buz masajı uygulaması ile akupresür tekniklerinin kıyaslandığı bir çalışmada; iki yöntemin etkili olduğu ancak buz masajının, akupresüre göre daha etkili olduğu bulunmuştur (Hajiamini, Msoud, Ebadi, Mahboubh \& Matin, 2012). Sırt masajı ve pozisyon değişiminin kıyaslandığı bir çalışmada ise; ağrıyı azaltma açısından sırt masajının pozisyon değişikliğinden daha etkili olduğu bildirilmiştir (Ali \& Hamdia, 2018). Yapılan çalışmalarda masajın doğum ağrısı ile başa çıkmak için uygun bir yöntem olduğu (Karami, Safarzadeh \& Fathizadeh, 2007; Hashemi, Badakhsh, Shahdadi, Heydari \& Hashemi, 2012; Tektaş, Akay, Mak ve Ay, 2017) belirtilirken, sistematik derlemelerde de masajın doğum ağrısını azaltmakta faydalı olduğu (Ganji, Jafari \& Keramat, 2015; Ranjbaran, Khorsandi, Matourypour \& Shamsi, 2017); ağrıy azaltmada, doğumun süresini kısaltmada ve kadınların kontrol duygusunu ve doğumun duygusal deneyimini iyileştirmede, masajın önemli bir role sahip olduğu bildirilmiştir (Smith et al., 2018).

\section{Farmakolojik Olmayan Yöntemlerin Avantajları}

Farmakolojik olmayan yöntemler; ağrı hissini ve farmakolojik ajan kullanımı ile gereksinimini azaltma konusunda etkilidir (Lawrence et al., 2013; Madden et al., 2016; Payendah et al., 2017; Regis et al. 2017; Shahoei et al., 2017; Veyilmuthu et al., 2017; Suarez et al., 2019). Aynı zamanda ağrıy1 azaltma konusunda farmakolojik olan yöntemlerle karşılaştırılabilir düzeyde veya daha üstündür (Simkin \& Bolding, 2004; Allameh et al., 2015; Payendah et al., 2017). Bu yüzden analjeziklerin yerine tercih edilebilir. Hekim istemine gerek duyulmamaktadır. Kullanımı kolay ve ucuz olup etkinliğini artırmak için birçok yöntem bir arada kullanılabilir. Kadına özgüven ve kontrol duygusunu verir, anksiyetesini azaltır ve kadının iş birliği ile aktif katılımını sağlar (Kömürcü, 2013).

\section{Farmakolojik Olmayan Yöntemlerin Dezavantajları}

Uygulanan bazı yöntemler ek güvenlik önlemi gerektirebilir. Yöntemlerin kullanımı yaygın değildir. Yöntemler ile ilgili yapılan çalışma sayısı azdır bu yüzden daha fazla çalışmaya ihtiyaç vardır. Öğrenme ve uygulama için zaman gerekir. Ebe sürekli meşgul olabilir (Kömürcü, 2013).

\section{Farmakolojik Olmayan Yöntemlerin Kullanılmasında Ebenin Rolü}

Gebeleri doğum sürecine hazırlamak ve pozitif doğum deneyimi yaşamalarını sağlamak, ebenin önemli rolleri arasındadır. Gebenin, doğum öncesinde doğum konusunda sahip olduğu bilgiler değerlendirilmeli, doğum ağrısıyla baş etmede her gebeye özgü bakım planı yapılmalıdır. Ebeler, 
gebelerin doğuma dair anksiyete ve korkularını azaltmada önemli sorumluluklara sahiptir (Karaçam ve Akyüz, 2011; Kömürcü, 2013; İpek, 2014; Türkmen, 2017).

Doğum ağrısını yönetebilmek için; öncelikli olarak gebenin algısını ve odağını bu yönetime yönlendirmeli, farkındalık oluşturulmalıdır. Ebe, annenin beklentilerini öğrenmeli ve kadına farmakolojik olmayan yöntemleri sunmalıdır. Gebenin içsel yeteneklerini destekleyen obstetrik uygulamaları sağlamalıdır. Hormonal aktiviteyi optimize ederek, doğum eyleminin fizyolojik olarak başlamasına izin vermelidir. Doğal oksitosin salınımını teşvik etmek için; anne ve fetüsü, mahremiyeti korumalı, kadının kendisini güvende hissetmesini sağlamalıdır. Doğumun fizyolojisine saygı duyarak, müdahalelerden kaçınmalı ve gebenin istediği şekilde hareket etmesine, hidrasyonuna ve beslenmesine engel olmamalıdır. Gebelerin soru sormasını desteklemeli, gerekli bilgiyi vermelidir. Doğumda sürekli ve duygusal yönden kadını desteklemelidir. Gebenin algısını ağrının yönetilebileceği yönünde değiştirdikten sonra, farmakolojik olmayan yöntemleri uygulamak için gebe ile birlikte karar vermelidir (Türkmen, 2017; Bonapace et al., 2018).

Ebe fiziksel, duygusal, bilgilendirici ve savunucu yönden sürekli destek sağlayarak; anneye, kendisine güvenmesini ve yapabileceğini aşılamalıdır. Kadını "Güzel 1kınıyorsun, bebeğini iyi ilerlettin", "Bu kasılmalar şiddetli fakat sen çok iyi başa çıkabiliyorsun.”, "Her şey yolunda gidiyor, olması gerektiği gibi ilerliyor." ve benzeri geri bildirimlerle cesaretlendirmeli ve gebenin alınan kararlara katılımasını teşvik etmelidir. Stressiz, loş ışıklı sakin bir ortam yaratarak, kadının kendini korunmuş ve güvende hissetmesini sağlamalıdır. Gebe hazır olduğunda, ağrısı ile başa çıkabilmek için, gebenin istediği yöntemi ebe uygulamalıdır. Annenin farmakolojik olmayan yöntem deneyimini anlayabilmek, memnuniyeti ve ağrıyı değerlendirebilmek için, kapalı uçlu ve olumsuz dil yerine, açık uçlu ve olumlu dili kullanarak (“Ağrınız var mı?” yerine "Şimdi nasıl hissediyorsunuz?”) sorular sormalıdır. Ebe ağrıyı ve yöntemi değerlendirip, gerektiğinde alternatif olarak; masaj, akupunktur, aromaterapi, hidroterapi, müzik gibi diğer farmakolojik olmayan yöntemleri önermeli ve sırasıyla denemelidir. Birden fazla farmakolojik olmayan yöntemi (masaj ve müzik, hipnoz ve müzik, aromaterapi, müzik ve hidroterapi vb.) bir arada uygulayabilir (Karaçam ve Akyüz, 2011; Bonapace et al., 2018).

Doğum sürecinde gebenin hakkını ebeler savunmalıdır. Doğumun destekçisi olarak ebeler, gebeye yardım etme, gebenin ihtiyaçlarını karşılama, konforunu sağlama, benlik saygısını artırmada her kadına özgü destekleyici bakım ve ebelik hizmeti sağlamalıdır. Ebeler doğum sonuçlarını geliştirme, gebenin pozitif doğum deneyimi yaşamasını sağlama, ebeveynlik rolüne uyum sürecini hızlandırma ve anne bebek bağlanmasını sağlamada öncülük etmelidir. Doğumun her aşamasında, kadına ve verdiği tepkilere duyarlı ve saygı olmalı, yargılayıcı olmamalı, kadının haklarını korumalı ve güvenliğini sağlamalı, isteklerini söyleyebilmesi için cesaretlendirmelidir (Karaçam ve Akyüz, 2011; Kömürcü, 2013; İpek, 2014; Türkmen, 2017). 
Ebeler farmakolojik olmayan yöntemlerin kullanılmasında aktif rol almalıdır. Araştırmaları yakından takip etmelidir. Kanıta dayalı yaklaşım göstererek ebelik bakımı sunmalıdır. Farmakolojik olmayan yöntemi/yöntemleri gebe ile birlikte karar vererek uygulamalı, olumlu ve olumsuz yönlerini tartışmalıdır. Farmakolojik olmayan yöntemlerin uygulanması, hekim istemi gerektirmeyen ve yan etkinin en az düzeyde olması nedeniyle ebeler tarafından bağımsız olarak güvenle uygulanabilmektedir (Karaçam ve Akyüz, 2011; Kömürcü, 2013; İpek, 2014; Türkmen, 2017).

\section{SONUÇ}

Doğum her kadın için çok özel bir süreçtir. Bir kadının gerçekleştirdiği bütün doğumlar tıpkı parmak izi gibi birbirinden farklıdır ve ayrı bir önem taşımaktadır. Bu kadar önem taşıyan bu süreçte kadının en yakınında olan temel destekçi kişi ebedir.

Doğum eyleminde yaşanan ağrı, doğum eyleminin seyrini etkilemektedir. Bu yüzden kadına; doğum öncesi dönemde, doğum ağrısı ile başa çıkmada farmakolojik olmayan yöntemleri ve doğum hakkında diğer bilgileri içeren eğitim verilmesi, doğum eylemi sırasında annenin bilinçli olmasını sağlamaktadır. Ebeler prepartum dönemde eğitimlerine başlayarak gebeyi bu sürece hazırlamalıdır. Gebenin psikolojik olarak doğuma hazır olması, doğum sürecini olumlu etkilemektedir.

Ebeler doğum sürecinde yaşanan ağrıda, gebe ile birlikte karar vererek farmakolojik olmayan yöntem veya yöntemleri uygulamalıdır. Hekim istemine gerek olmadığından; ebenin otonomisi ile karar ve bakım vermesi ön plandadır. Doğum ağrısının yönetimi ancak iyi bir ebelik bakımı ile sağlanabilir. Ebe tarafından iyi yönetilmiş doğum ağrısı ve süreci; gebenin olumlu bir doğum deneyimi yaşamasını, pozitif ebelik algısı oluşturmasını ve olası sonraki doğumlarını ebesi ile tercih etmesini sağlayabilir. Bu yüzden, ebeler her kadın için bireyselleştirilmiş nitelikli ebelik bakımı sağlamalıdır.

Ebeler doğum ağrısında farmakolojik olmayan yöntemleri yakından takip etmeli, hizmet içi eğitimlerle pekiştirmeli ve kanıt temelli yaklaşımlarla birleştirerek uygulamalıdır. 


\section{KAYNAKLAR}

Ali, S. A-S. K., \& Hamdia, M. A. (2018). Effect of change in position and back massage on pain perception during first stage of labor. Pain Management Nursing, 19(3), 288-94. doi: 10.1016/j.pmn.2018.01.006

Ahmad-Shirvani, M., \& Ganji, J. (2016). Comparison of separate and intermittent heat and cold therapy in labour pain management. Nursing Practice Today, 3(4): 179-86. http://npt.tums.ac.ir

Allameh, Z., Tehrani, H. G., \& Ghasemi, M. (2015). Comparing the impact of acupuncture and pethidine on reducing labor pain. Advanced Biomedical Research, 4(46). doi: 10.4103/22779175.151302

Altıparmak, S., ve Coşkun, A. M. (2016). Doğum öncesi verilen eğitimin gebenin bilgi düzeyi ile memnuniyet durumuna etkisi. Journal of Human Sciences, 13(2), 2610-24. doi: 10.14687/jhs.v13i2.3744

Askari, M., Alavi, A., \& Dashtinezhad, E. (2016). Effect of back massage with sesames oil on pain and lenght of delivery in primiparous women. The Iranian Journal of Obstetrics, Gynecology and Infertility, $18 \quad$ (183), $12-9$. https://www.researchgate.net/publication/309582458 Effect of back massage with sesames _oil_on_pain_and_length_of_delivery_in_primiparous_women

Barbieri, M., Henrique, A. J., Chors, F. M., Maia, NDeL., \& Gabrielloni, M. C. (2013). Banho quente de aspersao, exercisios perineais com bola suiça e dor no trabalho de parto. Acta Paulista De Enfermagem, 26(5). doi: 10.1590/S0103-21002013000500012

Bolbol-Haghighi, N., Masoumi, S. Z., \& Kazemi, F. (2016). Effect of massage therapy on duration of labour: a randomized controlled trial. Journal of Clinical \& Diagnostic Research, 10(4), 12-5. doi: 10.7860/JCDR/2016/17447.7688

Bonapace, J., Gagné, G., Challet, N., Gagnon, R., Hébert, E., \& Buckley, S. (2018). No.355Physiologic basis of pain in labour and delivery: an evidence-based approach to its management. Journal of Obstetrics Gynaecology Canada, 40 (2), 227-45. doi: 10.1016/j.jogc.2017.08.003

Derry, S., Straube, S., Moore, R. A., Hancock, H., \& Collins, S. L. (2012). Intracutaneous or subcutaneous sterile water injection compared with blinded controls for pain management in labour. Cochrane Database of Systematic Reviews. doi: 10.1002/14651858.CD009107.pub2 
Dong, C., Hu, L., Liang, F., \& Songying, Z. (2015). Effects of electro-acupuncture on labor pain management. Archives of Gynecology and Obstetrics, 291 (3), 531-6. doi: 10.1007/s00404014-3427-x

Fogarty, V. (2008). Intradermal sterile water injections for the relief of low back pain in labour: a systematic review of the literature. Women Birth. 21 (4): 157-63. doi: 10.1016/j.wombi.2008.08.003

Ganji, J., Jafari, Z., \& Keramat, A. (2015). The effectiveness of massage on labor pain and duration of labor: systematic review. The Iranian Journal of Obstetrics, Gynecology and Infertility, 18(158),19-27. Erişim Adresi: https://www.researchgate.net/publication/282940000_The_effectiveness_of_massage_on_labo r_pain_and_duration_of_labor_Systematic_review

Gaskin, I. M. (2015). Ina May'in Doğuma Hazırlık Rehberi. (Birinci Bask1) İstanbul: Sinek Sekiz Yayınevi. s.185-367.

Ghani, R. M. A. (2014). Effect of heat and cold therapy during the first stage of labor on women perception of birth experience: a randomized controlled trial. Journal Biology, Agriculture and Healthcare, 4(26). https://www.iiste.org/Journals/index.php/JBAH/article/view/17411/17833

Ghiasi, A., Bagheri, L., \& Haseli, A. (2019). A systematic review on the anxiolytic effect of aromatherapy during the first stage of labor. Journal of Caring Sciences, 8(1), 51-60. doi: $10.15171 /$ jcs.2019.008

Gonzalez, M. N., Trehan, G., \& Kamel, I. (2016). Pain management during labor part I: pathophysiology of labor pain and maternal evaluation for labor analgesia. Topics in Obstetrics \& Gynecology Practical CME Newsletter for Clinicians, 36 (11). https://www.deepdyve.com/lp/wolters-kluwer-health/pain-management-during-labor-part-1pathophysiology-of-labor-pain-and-GIl0WH0HY9 (Erişim Tarihi: 14.04.2019)

Gönenç, M. İ., ve Çakırer Çalbayram, N. (2017). Gebelerin, gebe okulu programı hakkındaki görüşleri ve eğitim sonrası deneyimleri. Journal of Human Sciences, 14(2): 1609-20. doi: 10.14687/jhs.v14i2.4424

Hajiamini, Z., Msoud, S. N., Ebadi, A., Mahboubh, A., \& Matin, A. A. (2012). Comparing the effects of 1ce massage and acupressure on labor pain reduction. Complementary Therapies in Clinical Practice, 18 (3): 169-72. doi: 10.1016/j.ctcp.2012.05.003

Hashemi, Z. S., Badakhsh, M., Shahdadi, H., Heydari, M., \& Hashemi, N. S. (2012). The effect on massage on intensity and duration of labor pain primigravida women in Zabol 
Amiralmoemenin Hospital. Journal of Zabol University of Medical Sciences and Health Services, 4(1): 85-93. https://www.sid.ir/en/journal/ViewPaper.aspx?id=439134

Hu, J., Brettle, A., Jiang, Z., \& Zeng, Y. (2017). A systematic review and meta-analysis of the effect of massage therapy in pain relief during labor. Journal of Nursing, 6(4): 1-14. doi:10.18686/jn.v6i4.130

Hutton, E. K., Kasperink, M., Rutten, M., Reitsma, A., \& Wainman, B. (2009). Sterile water injection for labour pain: a systematic review and meta-analysis of randomised controlled trials. BJOG An International Journal Of Obstetrics \& Gynaecology, 116 (9): 1158-66. doi: 10.1111/j.1471-0528.2009.02221.x

İpek, A. (2014). Doğum eyleminde alt strt bölgesine uygulanan derisel terapi yöntemlerinin doğum ăgrısı algısına ve doğumun süresine etkisi. (Yayımlanmamış Yüksek Lisans Tezi). Atatürk Üniversitesi Sağlık Bilimleri Enstitüsü, Erzurum.

Karaçam, Z., ve Akyüz, E. Ö. (2011). Doğum eyleminde verilen destekleyici bakım ve ebe / hemşirenin rolü. İstanbul Üniversitesi Florence Nightingale Hemşirelik Dergisi, 19 (1), s4553. ISSN 1304-4869. https://docplayer.biz.tr/14479560-Dogum-eyleminde-verilendestekleyici-bakim-ve-ebe-hemsirenin-rolu.html

Karami, K. N., Safarzadeh, A., \& Fathizadeh, N. (2007). Effect on massage therapy on severity of pain and outcome of labor in primipara. Iranian Journal of Nursing and Midwifery Research, 12(1).6-9. http://ijnmr.mui.ac.ir/index.php/ijnmr/article/view/2/2

Kömürcü, N. (2013). Doğum Ağrısı ve Yönetimi. (Birinci Bask1). İstanbul. Nobel Tıp Kitabevleri. s.14.

Lakhan, S. E., Sheafer. H., \& Tepper, D. (2016). The effectiveness of aromatherapy in reducing pain: a systematic review and meta-analysis. Pain Research and Treatment, 7, 1-13. doi: $10.1155 / 2016 / 8158693$

Lawrence, A., Lewis, L., Hofmeyr, G. J., \& Styles, C. (2013). Maternal position and mobility during first stage labour. Cochrane Database of Systematic Reviews. doi: 10.1002/14651858.CD003934.pub2

Madden, K., Middleton, P., Cyna, A. M., Matthewson, M., \& Jones, L. (2016). Hypnosis for pain management during labor and childbirth. Cochrane Database of Systematic Reviews. doi: 10.1002/14651858.CD009356.pub2

Mamuk, R. (2017). Lumbosakral bölgeye uygulanan intradermal steril su enjeksiyonunun doğumda ağrl algısına etkisi. (Yayımlanmamış Doktora Tezi). İstanbul Üniversitesi Sağlık Bilimleri Enstitüsü, İstanbul. 
Mardliyana, N. E, Raden, A., \& Hani, U. (2017). Effect of 1ce gel compress towards labor pain during active phase stage I at private midwifery clinics in Surabaya city area. Majalah Obstetri \& Ginekologi, $\quad 25 \quad$ (1): 21-4. https://pdfs.semanticscholar.org/ac78/93d778485d4d74abb37e061a7b4dd4f18ba9.pdf

Martensson, L. B., Hutton, E. K., Lee, N., Kildea, S., Gao, Y., \& Bergh, I. (2018). Sterile water injections for childbirth pain: an evidenced based guide to practice. Women Birth, 31 (5): 3805. doi: 10.1016/j.wombi.2017.12.001

Mollamahmutoğlu, L., Moraloğlu, Ö., Özyer, Ş., Akın Su, F., Karayalçın, R., Hançerlioğlu, N., et al. (2012). The effects of 1mmersion in water on labor, birth and newborn and comparison with epidural analgesia and conventional vaginal delivery. Journal of The Turkish-German Gynecologicak Association, 13 (1), 45-9. doi: 10.5152/jtgga.2012.03

Mortazavi, S. H., Khaki, S., Moradi, R., Heidari, K., \& Rahimparvar, S. F. V. (2012). Effects of massage therapy and presence of attendant on pain, anxiety and satisfaction during labor. Archives of Gynecology and Obstetrics, 286(1): 19-23. doi: 10.1007/s00404-012-2227-4

Payendah, M., Nassiri, M., Nahidi, F., \& Fouladi, A. (2017). Comparison of effects of transcutaneous electrical nerve stimulation with those of pharmaceuyical hyoscine- promethazine compound on pain intenstiy during the fist phase of labor. The Journal of Urmia University of Medical Sciences, 28 (9), 582-8. http://umj.umsu.ac.ir/browse.php?a id=4025\&sid=1\&slc lang=en (Erişim Tarihi: 07.02.2019)

Rajiani, I., Hendra, M., Sudirman, Sumami, Hartati. (2019). Application of digital rubbing massage in pain level, comfort and duration of labor phase. Indian Journal of Public Health Research \& Development, 10(1): 391-5. doi: 10.7860/JCDR/2016/17447.7688

Ranjbaran, M., Khorsandi, M., Matourypour, P., \& Shamsi, M. (2017). Effect of massage therapy on labor pain reduction in primiparous women: a systematic review and meta-analysis of randomized controlled clinical trials in Iran. Iran Journal of Nursing Midwifery Research, 22(4). 257-61. doi: 10.4103/ijnmr.IJNMR_109_16

Rastegarzade, H., Abedi, P., Valiani, M., \& Haghighi, M. H. (2015). The effect of auriculotherapy on labor pain intensity in nulliparous women. JAP, 6(3), 54-63. http://jap.iums.ac.ir/browse.php?a_code=A-10-247-1\&slc_lang=en\&sid=1 (Erişim Tarihi: 07.03.2019)

Regis, M. M., Honorio, GJdaS., Santos, KMdos., Luz Soraia, CTda., Luz, CMda., \& Roza, Tda. (2017). The effect of Transcutaneous Electrical Nerve Stimulation (TENS) and cryotherapy in the relief of pain during labor. Manual Therapy, Posturology \& Rehabilitation Journal, 15(461). doi: 10.17784/mtprehabjournal.2017.15.461 
Shahoei, R., Shahghebi, S., Rezai, M., \& Naqshbandi, S. (2017). The effect of transcutaneous electrical nerve stimulation on the severity of labor pain among nulliparous women: a clinical trial. Complementary Therapies In Clinical Practice, 28, 176-80. doi: 10.1016/j.ctcp.2017.05.004

Simkin, P., \& Bolding, A. (2004). Update on nonpharmacologic approaches to relieve labor pain and prevent suffering. Journal of Midwifery \& Women's Health, 49 (6). 489-504. doi: 10.1016/j.jmwh.2004.07.007

Smith, C. A., Levett, K. M., Collins, C. T., \& Jones, L. (2018). Massage, reflexology and other manual methods for pain management in labour. cochrane database of systematic reviews. doi: 10.1002/14651858.CD009290.pub2

Suarez, A. B., Castillo, E. M., Andujar, J. G., Hernandez, J. A. G., Montesdeoca, M. P. Q., \& Ferrer, J. F. L. (2019). Evaluation of the effectiveness of transcutaneous nerve stimulation during labor in breech presentation: a case series. The Journal of Maternal-Fetal \& Neonatal Medicine. doi: 10.1080/14767058.2019.1572110

Taavoni, S., Sheikhan, F., Abdolahian, S., \& Ghavi, F. (2016). Birth ball or heat therapy? A randomized controlled trial to compare the effectiveness of birth ball usage with sacrumperineal heat therapy in labor pain management. Complementary Therapies in Clinical Practice, 24, 99-102. doi: 10.1016/j.ctcp.2016.04.001

Tektaş, E., Akay, N., Mak, A. ve Ay, F. (2017). Vajinal doğumda ağrısının azaltılmasına yönelik nonfarmakolojik yöntemler ve masajın etkisi: 2000-2015 Yılları Tez Sonuçları. Sağllk Bilimleri ve Meslekleri Dergisi, 4(1): 64-70. doi: 10.17681/hsp.285574

Türkmen, H. (2017). Masaj ve sıcak uygulamanın doğum ăgrısı ve konfora etkisi. (Doktora Tezi). Ege Üniversitesi Sağl1k Bilimleri Enstitüsü, İzmir.

Vaziri, F., Farahmand, M., Samsami, A., Forouhari, S., Hadianfard, M. J., \& Sayadi, M. (2014). The effects of warm perineum compress during the second phase of labor on first-birth outcomes. Modern Care Journal, 11(1), 28-36. https://www.sid.ir/en/journal/ViewPaper.aspx?id=377868

Veyilmuthu, R., Govindan, S., Venugopalan, M., \& Panicker, S. (2017). effect of transcutaneous electrical nerve stimulation on labour pain relief among primigravida and multigravida mothers. International Journal of Reproduction, Contraception, Obstetrics and Gynecology, 6(3), 980-5. doi: 10.18203/2320-1770.ijrcog20170569

World Health Organization. (2017). WHO Managing Complications in Pregnancy and Childbirth: A Guide for Midwives and Doctors. Integrated Management of Pregnancy and Childbirth. 
Erișim

Tarihi

03.03.2019,

https://apps.who.int/iris/bitstream/handle/10665/255760/9789241565493-eng.pdf?sequence=1

Yılmaz Esencan, T., Karabulut, Ö., Demir Yıldırım, A., Ertuğrul Abbasoğlu, D., Külek, H., Şimşek, Ç., ve ark. (2018). Doğuma hazırlık eğitimi alan gebelerin doğum şekli, ilk emzirme zamanı ve ten tene temas tercihleri. FNJN Florence Nightingale Hemşirelik Dergisi, 26 (1): 31-43. doi: 10.26650/FNJN.387192 